Graphical Abstract
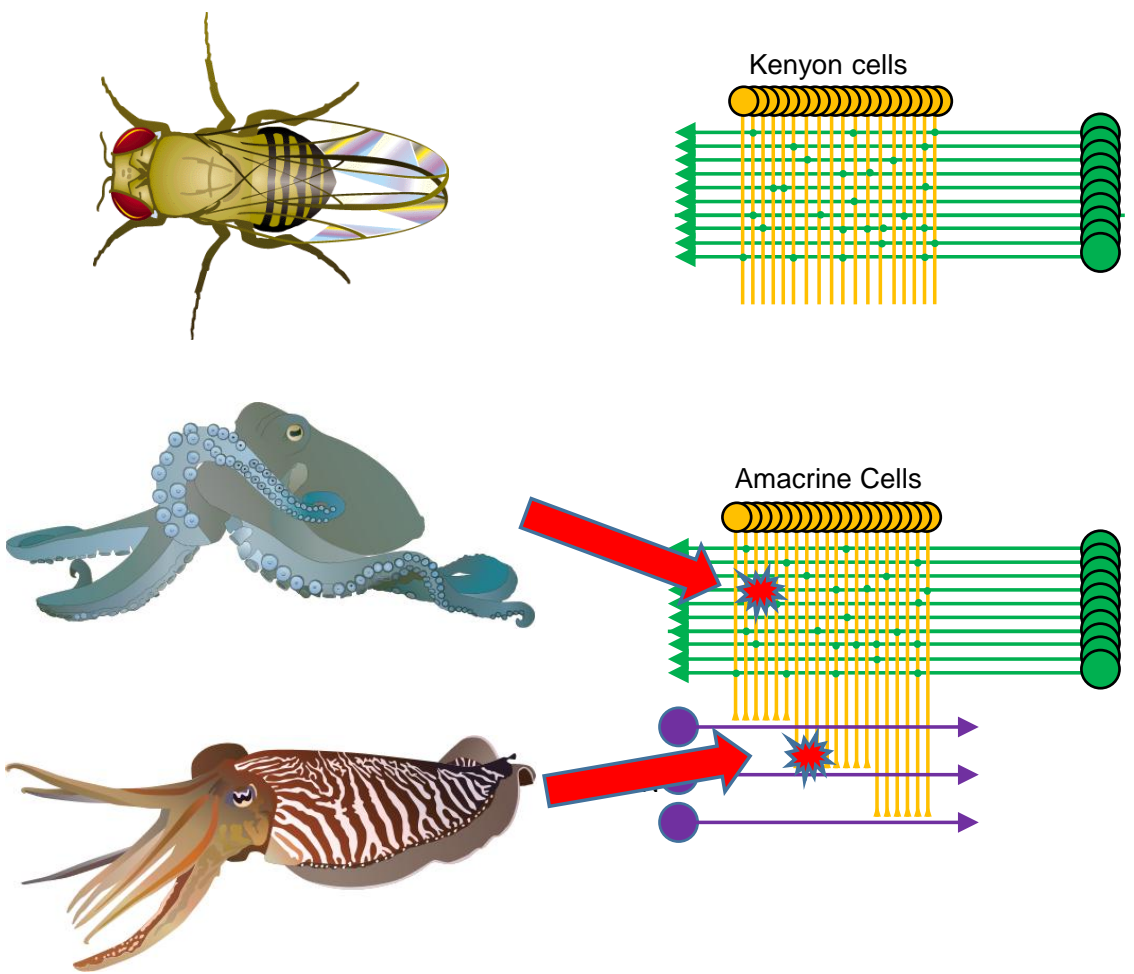

(C) 2016. This manuscript version is made available under the Elsevier user license http://www.elsevier.com/open-access/userlicense/1.0/ 


\title{
Phylogenetic plasticity in the evolution of molluscan neural circuits
}

Paul S. Katz

Neuroscience Institute

Georgia State University

PO Box 5030

Atlanta, GA 30302-5030 USA

pkatz@gsu.edu

\section{Submitted to Current Opinion in Neurobiology "Microcircuit computation and evolution" \\ Section Editors: Tom Clandinin and Eve Marder Volume 41}

\begin{abstract}
Recent research on molluscan nervous systems provides a unique perspective on the evolution of neural circuits. Molluscs evolved large, encephalized nervous systems independently from other phyla. Homologous body-patterning genes were re-specified in molluscs to create a plethora of body plans and nervous system organizations. Octopuses, having the largest brains of any invertebrate, independently evolved a learning circuit similar in organization and function to the mushroom body of insects and the hippocampus of mammals. In gastropods, homologous neurons have been re-specified for different functions. Even species exhibiting the similar, possibly homologous behavior have fundamental differences in the connectivity of the neurons underlying that behavior. Thus, molluscan nervous systems provide clear examples of re-purposing of homologous genes and neurons for neural circuits.
\end{abstract}

\section{Introduction}

"It is good to have hair-splitters \& lumpers." - Charles Darwin in letter to J. D. Hooker, 1857.

One of the most interesting theories to arise regarding the evolution of nervous systems is that neural centralization occurred in the ancestor of all bilaterian animals and that this common origin is reflected in the organization and patterns of homologous gene expression in the nervous systems of disparate organisms [1-3]. This has led some to speculate that there is deep homology between specific regions and circuits of arthropod, annelid, and vertebrate brains $\left[4,5,6^{*}, 7^{* *}\right]$. Darwin would have classified as "lumpers" the people who support the notion that complex nervous systems arose once. There are also "splitters" who argue that brains evolved several times and co-opted homologous genes [8-10]. The latter argument is based on a cladistic examination of extant nervous systems. These two hypotheses frame a discussion about the role of ancestry and genes in shaping the organization of neural circuits.

Analyses of brain evolution generally have not included molluscan nervous systems. This is a significant omission because molluscs, which include cephalopods, evolved large brains and high intelligence independently from vertebrates. Molluscs also include gastropods, which evolved a highly encephalized nervous system independently from cephalopods. Gastropod nervous systems have been important in neuroscience research because they contain 
individually identified neurons, allowing specific neural circuitry to be worked out and compared across species. Research on gastropods such as Aplysia has led to important discoveries that have implications across phyla [11-13]. Recent research on the evolution and development of molluscan nervous systems and neural circuits is filling this gap. These studies show that genes and neurons have been re-purposed in molluscs. They also show that similar neural networks have evolved independently in cephalopods and vertebrates. Conversely, different neural circuit configurations in gastropods produce similar behavioral outputs.

\section{The molluscan nervous system is not segmented}

Molluscs belong to Lophotrochozoa, which includes other major invertebrate phyla such as annelids and platyhelminthes (Fig. 1A). Lophotrochozoa is the sister group to Ecdysozoa. Mollusca is a diverse and ancient phylum ranging from worm-like animals, to snails, to octopuses, to clams. There are competing hypotheses regarding the deep phylogeny of molluscs including their position with respect to other lophotrochozoans as well as their split into the sister groups, Aculifera and Conchifera (Fig. 1A) [14*,15-17]. Although some Aculifera such as chitons (Polyplacaphora) appear to have segmented nervous systems, the apparent segmentation results from ladder-like nerves connecting two axon bundles [18]. Recent evidence from worm-like molluscs indicates that the last common ancestor of the Lophotrochozoa was not segmented; rather, segmentation arose secondarily in annelids [19*]. This is very important because it means that features of the segmented nervous systems in chordates that resemble those in segmented Lophotrochozoa such as worms are likely due to convergent evolution, not shared ancestry.

\section{Re-specification of morphogenic genes in the development of molluscan nervous systems}

Although molluscs are not segmented, some of them have similar gene expression profiles as other bilaterians for antero-posterior patterning genes [20]. For example, in cephalopods, as in most bilaterians, the Otx transcription factor gene is expressed anteriorly and is separated from posterior Hox expressing regions by Pax $2 / 5 / 8$ gene expression $\left[21,22^{* *}\right]$. However, based on the phylogeny, localization, and timing of expression it seems that Otx and Pax2/5/8 have been recruited for brain area specification in cephalopods independently from flies and mice, representing an example of convergent evolution of gene function [22**].

Molluscs have a complement of up to eleven Hox genes and three ParaHox genes $\left[23^{*}, 24^{\star}\right]$. The polyplacophoran mollusc, Acanthochitona crinita, exhibits co-linear expression along the antero-posterior axis, not just in the nervous system, but also in ecto-, endo-, and mesodermal tissue $\left[23^{*}, 24^{*}\right]$. However, gastropods, cephalopods, and probably other conchiferans have secondarily lost this co-linear expression pattern and express Hox genes in distinct organs, including portions of the nervous system [25] (Fig. 1B). Hox genes in cephalopods have complex temporal and spatial expression patterns during development $\left[26^{*}, 27\right]$. Several other developmental genes differ in their expression patterns from other bilaterians or are not expressed at all in the cephalopod brain $\left[28^{*}, 29^{*}\right]$. The ParaHox gene, Gsx has generally been thought to be involved in the formation of the foregut in protostomes. In gastropods it is expressed in the foregut and nervous system, whereas in scaphopods and cephalopods it is not expressed in the digestive system and is instead expressed in large portions of the nervous system [30]. The evolution of camera eyes in cephalopods also has involved re-specification of many genes into novel morphogenic pathways $\left[21,31^{* *}\right]$. It has been suggested that the great diversity of body forms in gastropods and cephalopods is caused by a recruitment of Hox and 
other morphogenic genes into novel functions through differences in their interactions and downstream effects $\left[26^{*}, 32,33\right]$. Thus, although molluscs share homologous genes for transcription factors, the recruitment of these genes for development of the nervous system differs.

\section{Convergent evolution of neural circuits in large-brained animals}

The brain of a cephalopod such as an octopus has hundreds of millions of neurons, rivalling in size and complexity that of many mammals [34,35]. Furthermore, cephalopods have highly organized neuropils with small neurons, reminiscent of vertebrate brains (Fig. 2A). Although the genome of the octopus is generally similar to that of other lophotrochozoans, it has undergone a large expansion of two gene families that were previously thought to be uniquely enlarged in vertebrates, including the protocadherins, which regulate neuronal development [36**]. This genetic convergence may have played a role in the convergent evolution of large brains.

In addition to having exceptionally large brains, octopuses and cuttlefish exhibit the highest degree of vertebrate-like intelligence for any invertebrate. The vertical lobe of octopus and cuttlefish is the brain area responsible for a variety of cognitive tasks including visual and tactile learning $\left[37^{* *}, 38,39\right]$. The organization of its inputs and outputs has been described as "fan-out / fan-in", where the sensory inputs likely are sparsified and multiplexed $\left[40^{* *}, 41\right]$. The output converges onto a smaller number of neurons (Fig. 2B). The organization is similar to that of the insect mushroom body, the hippocampus, and cerebellar-like structures [42-45]. Based on what we know about those other circuits, we can infer that the function in octopus is similar, namely to increase the dimensionality of the inputs in order to make more precise associations between stimuli.

\section{Plasticity in cephalopod learning circuits differs between octopus and cuttlefish}

As with the hippocampus, the cephalopod vertical lobe is amenable to electrophysiology in a slice preparation. In the octopus, SFL to AM synapses undergo several forms of plasticity including activity-dependent long term potentiation (LTP) [46]. Unlike the hippocampus, however, the postsynaptic neurons, the AM interneurons, are non-spiking. Although the presynaptic neurons are glutamatergic, LTP does not appear to involve NMDA receptors, but might depend on nitric oxide signaling $\left[40^{* *}\right]$.

Neuromodulatory inputs to the VL also affect synaptic transmission. Serotonin (5-HT) causes a short-term enhancement of SFL to AM synapses and decreases the threshold for evoking activity-dependent LTP [47]. Octopamine works in opposition to 5-HT, reducing the ability of high-frequency trains to elicit LTP at SFL to AM synapses [40**].

Although the circuit organization of the SFL - VL pathway in cuttlefish, another coleoid cephalopod, is very similar to that of octopus, the plasticity exhibited is completely different [48]. Whereas the octopus has both short and long-term plasticity, including serotonergic neuromodulation at the SFL to AM synapses (green dots, Fig. 2B), the cuttlefish shows no plasticity at these synapses. Conversely, the cuttlefish exhibits LTP at cholinergic AM to LN synapses (orange triangles), which show no plasticity in the octopus. Thus, homologous neurons exhibit differences in the plasticity of their synapses in two cephalopods that both are intelligent visual hunters. This indicates that there are multiple solutions to using this circuitry for learning and memory. 


\section{Gastropods use homologous neurons for different functions}

Numbering about 10,000 neurons [49], gastropod brains are orders of magnitude smaller than those of cephalopods. Yet, they are larger than other molluscs and, based on phylogenomics (Fig. 1A), represent an independent expansion of brain size.

Gastropods have many large, individually identifiable neurons, allowing homologous neurons to be recognized across species [50-53]. For example, the giant serotonin neuron is readily identified in the cerebral ganglion of most gastropods (Fig. 3) [54,55]. Serotonergic neurons are some of the earliest to develop in gastropod nervous systems [56-58]. These neurons form a network in the adult that plays an important role in behavioral arousal $[59,60]$. The five cerebral serotonergic posterior (CeSP, Fig.3) interneurons have been well studied in several species $[61,62]$. In Aplysia californica and Pleurobranchaea californica the CeSPs are activated by both noxious and food stimuli $[63,64]$. They synapse onto neurons that activate both feeding and locomotion.

Just as genes have been re-purposed for new functions, so have neurons. There are two basic forms of crawling in Heterobranchia (a subclade of Gastropoda), mucociliary gliding and muscular waves. In some species, the CeSP interneurons activate the efferent serotonergic and peptidergic neurons that project to the ciliated cells on the foot and thereby increase the rate of ciliary beating $[64,65]$. However, in species such as the anaspid Aplysia californica that have muscular waves, the CeSP interneurons cause an increase in the burst rate of the locomotor central pattern generator (CPG) in the pedal ganglion [63]. Although the nudibranch, Hermissenda crassicornis, has mucociliary crawling that is supplemented by muscular waves, the CeSP neurons have the opposite downstream action; they cause foot retraction and no increase in ciliary beating [66].

In addition to crawling, some Heterobranchia swim. The gymnosomatan Clione limacina never crawls; it is an obligate swimmer, flapping two wing-like parapodia [67]. The CeSP neurons arouse locomotion in Clione by causing an increase in the rate of wing flapping [68]. The nudibranch, Melibe leonina swims by flexing its body from left to right. Stimulation of the CeSPs can initiate the swim motor pattern or increase the rate and regularity of the motor activity underlying this side-to-side motion [69]. Thus, although these animals all share a set of homologous serotonergic neurons, their downstream targets have been re-specified for different behaviors or ecologies.

The re-specification of cerebral serotonergic neurons has gone one step further with their incorporation into a CPG for escape swimming in Tritonia [70,71] and Pleurobranchaea [72]. Escape swimming evolved independently in these two species, yet both have re-purposed the CeSP interneurons to be components of a CPG that generates bilaterally synchronous bursts of action potentials [73]. In addition, a peptidergic neuron, which has been identified in many other nudipleura species [51], has also been recruited into the escape swim circuit of both species.

The CeSPs in both Tritonia and Pleurobranchaea have neuromodulatory actions within the swim CPG that are not seen in a species that does not swim [74*]. This suggests that perhaps differences in 5-HT receptor expression might underlie the re-specification of these neurons as members of a swim CPG $\left[75^{* *}, 76\right]$.

It is conceptually easy to see how evolution of behavior might involve changes to neural circuitry to alter behavior. However, work on two nudibranchs that both exhibit similar forms of swimming and have homologous neurons has found that the neural circuits underlying similar behaviors 
can differ $\left[73,75^{* *}, 77,78\right]$. Melibe and another nudibranch, Dendronotus iris both swim with leftright flexions and their swim CPGs contain three pairs of neurons, which may be homologous $\left[79,80^{* *}\right]$. However, those neurons have different synaptic connectivity, which causes them to have different firing patterns during the swim motor pattern (Fig. 4). Thus, as with Cephalopods, there are multiple solutions to using a set of homologous neurons for the same function.

\section{Conclusions}

Molluscan neural circuitry represents a different evolutionary trajectory from vertebrates and even other lophotrochozoans. Using the same morphogenic genes as other phyla, they have created novel nervous systems that control a wide variety of body forms. Yet the largest brained invertebrates, the cephalopods, have converged with insects and vertebrates on the organization of circuitry for learning and memory. Even with this cross-phyletic convergence, there are intra-phyletic differences between octopus and cuttlefish in the sites of plasticity. Phylogenetic plasticity is also found in gastropods where homologous neurons have been reused for different functions and where neuromodulatory actions also display species-specificity. One outcome from this work is to show that there are many solutions to the same problem.

The story of molluscs is about how looks can be deceiving; the same genes and neurons can be used and reused in different ways to create diverse nervous systems that sometimes converge on the same solution. I think it is more exciting to realize that octopus and mammals independently came up with a learning machine that has a fan-out/fan-in organization and LTP than to think that these similarities are just a family resemblance. Call me a splitter, but I believe that uncovering the many solutions that nature has found will tell us more about fundamental organizational properties than lumping them all together.

\section{Acknowledgements}

The author would like to thank Tim Wollesen for his input with regard to molluscan phylogeny and development. The author's research is supported by grants from the National Science Foundation (IOS-1455527) and the March of Dimes Foundation (6-FY14-441). 
Figure Legends

\section{Figure 1.}

\section{Phylogeny of mollusca and a comparison of Hox gene expression.}

A. Phylogenetic tree showing the relationship of Mollusca to other major phyla and relationships of major molluscan clades. Many of the ancient relationships are still controversial. Within Mollusca, the tree is based on the phylogenomic work of $[16,17,81]$. The position of Monoplacophora, in particular, has been debated, as indicated by dashed lines and question mark. Although Scaphopodia, Bivalvia, Gastropoda are in a clade, there is disagreement as to whether Scaphopoda is a sister group to Bivalvia and Gastropoda. B. Comparison of Hox gene expression patterns in annelid, polyplacophoran, and gastropod trochophor larvae. Anterior is up in the image. As indicated by the colored bars on the left, there is an anterior-posterior progression of gene expression in the annelid and polyplacophoran larvae, but not in the gastropod where the genes are expressed in specific structures such as the prototroch (blue). The hair-like structures are tufts of cilia. The small circle represents the mouth and the ellipse is the ventral foot. Modified from [23*].

\section{Figure 2.}

\section{Organization of the octopus learning circuits}

A. An unstained sagittal section of the octopus brain illustrates the locations of neurons in the medial superior frontal lobes (MSFL) and the vertical lobe (VL). B. Diagrammatic representation of the connections from the superior frontal lobe (SFL) to the VL. The 1.8 million glutamatergic neurons in the SFL receive multimodal sensory inputs, in particular, visual input. SFL neurons synapse en passant with 25 million cholinergic amacrine (AM) interneurons in the VL. The amacrine interneurons then converge on a relatively small number $(65,000)$ of efferent large neurons (LNs). The LNs then project to premotor areas of the brain such as the subvertical lobe $(\mathrm{SV})$ and others in the basal lobes (BL) in such a way that plasticity in the SFL - VL circuit will alter the ultimate effect of the sensory input. The inferior frontal lobe (IFL) also has projections to the vertical lobe. Based on $\left[40^{* *}\right]$.

\section{Figure 3.}

\section{Serotonergic neurons in gastropods}

Using the nervous system of Aplysia californica as an example, the locations of serotonergic neurons in the nervous system are laid out. The Aplysia nervous system is typical of gastropods in having distinct ganglia connected via connectives and commissures. The giant serotonin neuron (GSN) is located in the anterior portion of each cerebral ganglion. The cerebral serotonin posterior (CeSP) neurons are a cluster of about five neurons located in the posterior part of the cerebral ganglion that form part of an arousal system, which activates other serotonergic neurons throughout the nervous system. CeSP is following the nomenclature of [59]. 


\section{Figure 4.}

The swim central pattern generators (CPGs) of two nudibranchs are composed of homologous neurons with different synaptic connectivity.

The CPG underlying swimming consisting of left-right alternations in Melibe leonina (A) and Dendronotus iris (B). There are three left/right pairs of homologous neurons called swim interneurons 1-3 (Si1, Si2, and Si3). In Melibe, Si1 makes and receives inhibition from the contralateral side (small circles), whereas in Dendronotus, Si1 only has electrotonic connections (resistor symbols). The synapse from Si3 to the contralateral Si2 is inhibitory in Melibe, but excitatory and electrotonic in Dendronotus. C. The swim motor pattern in Melibe is characterized by left-right alternation in each neuronal pair. Furthermore, bursts in $\mathrm{Si} 3$ follow those in the contralateral Si2 (red box). D. The dynamics of the swim interneuron activity differs in Dendronotus. Si1 is not rhythmically active. Si3 slightly leads the contralateral $\mathrm{Si} 2$, but is mostly coactive with it (red box). Based on results from $\left[77,79^{*}, 80^{* *}\right]$. 


\section{References}

1. Holland LZ, Carvalho JE, Escriva H, Laudet V, Schubert M, Shimeld SM, Yu JK: Evolution of bilaterian central nervous systems: a single origin? Evodevo. 2013, 4:27.

2. Lichtneckert $R$, Reichert $H$ : Insights into the urbilaterian brain: conserved genetic patterning mechanisms in insect and vertebrate brain development. Heredity 2005, 94:465-477.

3. Arendt D, Denes AS, Jekely G, Tessmar-Raible K: The evolution of nervous system centralization. Philos. Trans. R. Soc. Lond B Biol. Sci 2008, 363:1523-1528.

4. Strausfeld NJ, Hirth F: Deep homology of arthropod central complex and vertebrate basal ganglia. Science 2013, 340:157-161.

5. Tomer R, Denes AS, Tessmar-Raible K, Arendt D: Profiling by image registration reveals common origin of annelid mushroom bodies and vertebrate pallium. Cell 2010, 142:800-809.

6. Wolff $\mathrm{GH}$, Strausfeld NJ: Genealogical correspondence of a forebrain centre implies an executive brain in the protostome-deuterostome bilaterian ancestor. Philos Trans $R$ Soc Lond B Biol Sci 2016, 371:20150055.

* The authors make an argument that the insect mushroom body and the mammalian hippocampus are homologous based on a similarity in network architecture, intense immunostaining for the Protein Kinase A catalytic subunit (PKA-Ca) and phosphorylated $\mathrm{Ca}(2+) /$ calmodulin-dependent protein kinase II (pCaMKII). They claim that these similarities point to a shared origin for a learning circuit in the protostome-deuterostome bilaterian ancestor. They point to immunhistochemical staining in the anterior portion of the acoel nervous system as evidence for this shared ground plan.

7. Fiore VG, Dolan RJ, Strausfeld NJ, Hirth F: Evolutionarily conserved mechanisms for the selection and maintenance of behavioural activity. Philos Trans $R$ Soc Lond B Biol Sci 2015, 370.

** In this recent paper, the authors expand on the theory that the insect central complex and the vertebrate basal ganglia are homologous. They list anatomical, developmental, genetic, and functional similarities between the two structures. Both brain areas are important for action selection. The overall circuitry for action selection is compared between insects and vertebrates, including its modulation by dopamine. The conclusion is that the similarities arise from the presence of the circuitry in a common ancestor.

8. Farries MA: How 'basal' are the basal ganglia? Brain Behav. Evol 2013, 82:211-214.

9. Northcutt RG: Evolution of centralized nervous systems: Two schools of evolutionary thought. Proc Natl Acad Sci U. S A 2012, 109 Suppl 1:10626-10633.

10. Moroz LL: On the independent origins of complex brains and neurons. Brain Behav. Evol 2009, 74:177-190.

11. Pittenger $C$, Kandel $E R$ : In search of general mechanisms for long-lasting plasticity: Aplysia and the hippocampus. Philos. Trans. R. Soc. Lond B Biol Sci 2003, 358:757763.

12. Kandel ER: The molecular biology of memory storage: a dialogue between genes and synapses. Science 2001, 294:1030-1038.

13. Orlovsky GN, Deliagina TG, Grillner S: Neuronal Control of Locomotion: From Mollusc to Man. New York: Oxford University Press; 1999.

14. Schrodl M, Stoeger I: A review on deep molluscan phylogeny: old markers, integrative approaches, persistent problems. Journal of Natural History 2014:1-32. 
* In this comprehensive review, the authors present the latest data about the basal phylogenetic relationships of molluscs. They attempt to resolve discrepancies between trees produced with different approaches. The authors conclude that early molluscan diversification happened more rapidly than previously appreciated.

15. Simakov O, Marletaz F, Cho SJ, Edsinger-Gonzales E, Havlak P, Hellsten U, Kuo DH, Larsson T, LV J, Arendt D, et al.: Insights into bilaterian evolution from three spiralian genomes. Nature. 2013, 493:526-531.

16. Kocot KM, Cannon JT, Todt C, Citarella MR, Kohn AB, Meyer A, Santos SR, Schander C, Moroz LL, Lieb $B$, et al.: Phylogenomics reveals deep molluscan relationships. Nature 2011:452-456.

17. Smith SA, Wilson NG, Goetz FE, Feehery C, Andrade SC, Rouse GW, Giribet G, Dunn CW: Resolving the evolutionary relationships of molluscs with phylogenomic tools. Nature 2011, 480:364-367.

18. Friedrich S, Wanninger A, Bruckner M, Haszprunar G: Neurogenesis in the mossy chiton, Mopalia muscosa (Gould) (Polyplacophora): evidence against molluscan metamerism. J Morphol. 2002, 253:109-117.

19. Redl E, Scherholz M, Todt C, Wollesen T, Wanninger A: Development of the nervous system in Solenogastres (Mollusca) reveals putative ancestral spiralian features. Evodevo. 2014, 5:48.

* The researchers used 5-HT, a-tubulin, and FMRFamide immunoreactivity to study the the development of the nervous systems of two species of worm-like molluscs in the Solenogastres or Neomeniomorpha clade, whose phylogenetic placement within Aplacophora is debated. They found that the early development was very similar to that of conchiferans.

They compare nervous system development to other lophotrochozoans and conclude that the last common ancestor of this major invertebrate group had two lateral neurite bundles and that it was not segmented. Thus, the characteristic of tetraneury (4 nerve bundles) some molluscs is derived as is the flatworm ladder-like nerve cord.

20. Holland PW: Evolution of homeobox genes. Wiley. Interdiscip.Rev.Dev Biol 2013, 2:31-45.

21. Buresi A, Baratte S, Da SC, Bonnaud L: orthodenticlelotx ortholog expression in the anterior brain and eyes of Sepia officinalis (Mollusca, Cephalopoda). Gene Expr.Patterns. 2012, 12:109-116.

22. Wollesen T, Rodriguez Monje SV, Todt C, Degnan BM, Wanninger A: Ancestral role of Pax2/5/8 in molluscan brain and multimodal sensory system development. BMC.Evol.Biol. 2015, 15:231.

** This paper looks at the developmenal expression of Pax2/5/8 genes in representative species from both molluscan sister groups Aculifera and the Conchifera. They conclude from this work that these morphogenic genes have been independently recruited into brain regionalization and sensory organ development in molluscs.

23. Fritsch $M$, Wollesen $T$, de Oliveira $A L$, Wanninger A: Unexpected co-linearity of Hox gene expression in an aculiferan mollusk. BMC.Evol.Biol. 2015, 15:151.

* Prior to this study, it was known that Hox genes did not show collinear expression in cochiferan molluscs such as gastropods and cephalopods. This paper examined a chiton (Aculifera) and found that it resembled other lophotrochozoans in its Hox gene expression pattern. This indicates that the ancestral mollusc was similar to other lophotrochozoans in its anterior-posterior patterning, but that conchiferans lost this pattern, explaining their large morphological diversity. 
24. Fritsch M, Wollesen T, Wanninger A: Hox and ParaHox Gene Expression in Early Body Plan Patterning of Polyplacophoran Mollusks. J Exp Zool B Mol Dev Evol 2016.

* This paper looks at the expression of additional Hox and ParaHox genes in a chiton (Polyplacophora) and finds that in contrast to gastropods and cephalopods, these genes are expressed in a collinear anterior-posterior fashion that resembles annelids and other bilaterians. Providing more evidence that gastropods and cephalopods lost the ancestral pattern of Hox gene expression.

25. Samadi L, Steiner G: Expression of Hox genes during the larval development of the snail, Gibbula varia (L.)-further evidence of non-colinearity in molluscs. Dev Genes Evol 2010, 220:161-172.

26. Focareta L, Sesso S, Cole AG: Characterization of homeobox genes reveals sophisticated regionalization of the central nervous system in the European cuttlefish Sepia officinalis. PLoS One 2014, 9:e109627.

* The researchers examined the expression pattern of homeobox (Hox) genes in the ANTPPRD- and LIM-classes during development of the European Cuttlefish. As in insects and mammals ANTP-class gene expression is largely restricted to the posterior ganglia (the subesophageal mass). PRD-class HD gene expression is more prevalent in the anterior ganglia, the supraesophageal mass.

27. Lee PN, Callaerts $P$, De Couet HG, Martindale MQ: Cephalopod Hox genes and the origin of morphological novelties. Nature 2003, 424:1061-1065.

28. Navet S, Barattez S, Bassaglia Y, Andouche A, Buresi A, Bonnaud L: Neurogenesis in cephalopods: "Eco-Evo-Devo" approach in the cuttlefish Sepia offinicalis (Mollusca-Cephalopoda). Journal of Marine Science and Technology-Taiwan 2014, 22:15-24.

* In this review, the authors explain the morphogenic development of cephalopods and how it compares to that of gastropods. They review the genetic basis for this morphology, specifically discussing Engrailed, Pax6, Shh, Otx, and Elav.

29. Bonnaud-Ponticelli L, Bassaglia Y: Cephalopod development: what we can learn from differences. OA Biology 2014, 2:6.

* In this short review, the authors explain how cephalopods have evolved such unique body plans by recruiting morphogenic gene pathways in novel ways. Hox genes are not used for antero-posterior axis patterning, but instead are used for specific organs.

30. Wollesen T, Rodriguez Monje SV, McDougall C, Degnan BM, Wanninger A: The ParaHox gene Gsx patterns the apical organ and central nervous system but not the foregut in scaphopod and cephalopod mollusks. Evodevo 2015, 6:41.

* The ParaHox gene Gsx was hypothesized to pattern the foregut of the ancestral bilaterian. Here it is shown that in a scaphopod and a cephalopod, the gene is not expressed in the foregut. Instead, it is found in the apical organ of scaphopod trochophore larvae and in two cells adjacent to it.

31. Yoshida MA, Ogura A, Ikeo K, Shigeno S, Moritaki T, Winters GC, Kohn AB, Moroz LL: Molecular evidence for convergence and parallelism in evolution of complex brains of cephalopod molluscs: Insights from visual systems. Integr.Comp Biol 2015, 55:1070-1083. 
** This paper examines the genetic mechanisms underlying the convergent evolution of vertebrate-like retinal eyes in cephalopods. The researchers performed RNA sequencing and in situ hybridization on the eyes of pygmy squid and nautilus. They found that genes homolgous to those in vertebrates are recruited for different functions in the visual system and that convergent structures such as the lens have different developmental mechanisms. Like vertebrates, cephalopods have an independent expansion of opsin genes, however in squid, they include ciliary opsins, rhabdomeric opsins, and some novel opsins. Another molecular component of the visual pathway, the arrestins have undergone an expansion in squid. Thus, the convergent evolution of a camera-type eye in squid has involved expansion of some gene classes, reorganization of gene networks and recruitment of genes into novel functions.

32. Navet S, Andouche A, Baratte S, Bonnaud L: Shh and Pax6 have unconventional expression patterns in embryonic morphogenesis in Sepia officinalis (Cephalopoda). Gene Expr.Patterns. 2009, 9:461-467.

33. Biscotti MA, Canapa A, Forconi M, Barucca M: Hox and ParaHox genes: A review on molluscs. Genesis. 2014, 52:935-945.

34. Grasso FW, Basil JA: The evolution of flexible behavioral repertoires in cephalopod molluscs. Brain Behav. Evol 2009, 74:231-245.

35. Wollesen $T$, Loesel $R$, Wanninger A: Pygmy squids and giant brains: mapping the complex cephalopod CNS by phalloidin staining of vibratome sections and wholemount preparations. J.Neurosci.Methods. 2009, 179:63-67.

36. Albertin CB, Simakov O, Mitros T, Wang ZY, Pungor JR, Edsinger-Gonzales E, Brenner S, Ragsdale CW, Rokhsar DS: The octopus genome and the evolution of cephalopod neural and morphological novelties. Nature 2015, 524:220-224.

** The researchers sequenced the whole genome of Octopus bimaculoides and several tissuespecific transcriptomes. They found an expansion of two gene families that were previously thought to be unique to vertebrates: the protocadherins, which regulate neuronal development, and the $\mathrm{C} 2 \mathrm{H} 2$ superfamily of zinc-finger transcription factors. They also found that octopuses and limpets (a gastropod) have three genes in the DLG family, which previously was associated with vertebrate synaptic complexity. They found an octopusspecific class of short interspersed nuclear element sequences expressed in neural tissue, which has been suggested to play a role in learning and memory.

37. Shigeno S, Ragsdale CW: The gyri of the octopus vertical lobe have distinct neurochemical identities. J Comp Neurol 2015, 523:1297-1317.

** This research paper also contains an excellent primer on the anatomy of the octopus brain. They show that the lobes and gyri of the octopus brain are neurochemically distinct. In particular, the presence or absence of fascicles that are immunoreactive to octopus GNRH peptide (oGNRH) delineate transverse zones in the SFL. The vertical lobe in octopus is characterized by five gyri. The two lateral gyri stain for oGNRH, whereas the medial three gyri are distinguished by octopressin-neurophysin (OP-NP) staining. Serotonin staining was also differentially distributed, particularly in hatchlings.

38. Boycott BB, Young JZ: A Memory System in Octopus vulgaris Lamarck. Proceedings of the Royal Society of London B: Biological Sciences 1955, 143:449-480.

39. Shomrat T, Zarrella I, Fiorito G, Hochner B: The octopus vertical lobe modulates shortterm learning rate and uses LTP to acquire long-term memory. Curr. Biol 2008, 18:337-342.

40. Shomrat T, Turchetti-Maia AL, Stern-Mentch N, Basil JA, Hochner B: The vertical lobe of cephalopods: an attractive brain structure for understanding the evolution of 
advanced learning and memory systems. J Comp Physiol A Neuroethol Sens Neural Behav Physiol 2015, 201:947-956.

** This review paper has a full description of the vertical lobe system and its plasticity in cephalopods. The authors provide a brief overview of molluscan and cephalopod phylogeny. They discuss the organization of the octopus vertical lobe circuitry, its pharmacology, and its synaptic plasticity, both activity-dependent and neuromodulatory. They contrast the plasticity of cuttlefish and octopus vertical lobe plasticity, which have the same circuitry, but diametrically different locations of plasticity.

41. Hochner B: Functional and comparative assessments of the octopus learning and memory system. Front Biosci (Schol Ed) 2010, 2:764-771.

42. Farris SM: Are mushroom bodies cerebellum-like structures? Arthropod Struct Dev 2011, 40:368-379.

43. Fahrbach SE: Structure of the mushroom bodies of the insect brain. Annu Rev Entomol 2006, 51:209-232.

44. Bell CC, Han V, Sawtell NB: Cerebellum-Like Structures and Their Implications for Cerebellar Function. Annu. Rev. Neurosci 2008, 31:1-24.

45. Turner DA, Buhl EH, Hailer NP, Nitsch R: Morphological features of the entorhinalhippocampal connection. Prog Neurobiol 1998, 55:537-562.

46. Hochner B, Brown ER, Langella M, Shomrat T, Fiorito G: A learning and memory area in the octopus brain manifests a vertebrate-like long-term potentiation. $J$ Neurophysiol 2003, 90:3547-3554.

47. Shomrat T, Feinstein N, Klein M, Hochner B: Serotonin is a facilitatory neuromodulator of synaptic transmission and "reinforces" long-term potentiation induction in the vertical lobe of Octopus vulgaris. Neuroscience 2010, 169:52-64.

48. Shomrat T, Graindorge N, Bellanger C, Fiorito G, Loewenstein Y, Hochner B: Alternative sites of synaptic plasticity in two homologous "fan-out fan-in" learning and memory networks. Curr Biol 2011, 21:1773-1782.

49. Cash D, Carew TJ: A quantitative analysis of the development of the central nervous system in juvenile Aplysia californica. J Neurobiol 1989, 20:25-47.

50. Croll RP: Identified neurons and cellular homologies. In Nervous Systems in Invertebrates. Edited by Ali MA: Plenum Publishing Corp.; 1987:41-59.

51. Lillvis JL, Gunaratne CA, Katz PS: Neurochemical and neuroanatomical identification of central pattern generator neuron homologues in nudipleura molluscs. PLOS. ONE 2012, 7:e31737.

52. Baltzley MJ, Sherman A, Cain SD, Lohmann KJ: Conservation of a Tritonia Pedal peptides network in gastropods. Invertebrate Biology 2011, 130:313-324.

53. Bulloch AGM, Ridgway RL: Comparative aspects of gastropod neurobiology. In The Nervous Systems of Invertebrates: An Evolutionary and Comparative Approach: With a Coda written by T.H. Bullock. Edited by Breidbach O, Kutsch W: Birkhäuser Basel; 1995:89-113.

54. Weiss KR, Kupfermann I: Homology of the giant serotonergic neurons (metacerebral cells) in Aplysia and pulmonate molluscs. Brain Res 1976, 117:33-49.

55. Pentreath VW, Berry MS, Osborne NN: The serotonergic cerebral cells in gastropods. In Biology of Serotonergic Transmission. Edited by Osborne NN: John Wiley \& Sons; 1982:457-513.

56. Franchini A: The distribution of cells containing FMRFamide- and 5-HT-related molecules in the embryonic development of Viviparus ater (Mollusca, Gastropoda). Eur. J. Histochem 2005, 49:301-308.

57. Croll RP: Developing nervous systems in molluscs: navigating the twists and turns of a complex life cycle. Brain Behav. Evol 2009, 74:164-176. 
58. Wanninger A, Wollesen T: Mollusca. In Evolutionary Developmental Biology of Invertebrates, Vol. 2 Lophotrochozoa (Spiralia). Edited by Wanniger E: Springer; 2015:103-153.

* This recent book chapter provides a wonderful overview of the phylum Mollusca. In particular, it reviews early development and the origin of the nervous system.

59. Marinesco S, Kolkman KE, Carew TJ: Serotonergic modulation in Aplysia: I. A distributed serotonergic network persistently activated by sensitizing stimuli. $J$ Neurophysiol 2004, 92:2468-2486.

60. Jing J, Gillette R, Weiss KR: Evolving Concepts of Arousal: Insights from Simple Model Systems. Reviews in the Neurosciences 2009, 20:405-427.

61. Katz PS, Fickbohm DJ, Lynn-Bullock CP: Evidence that the swim central pattern generator of Tritonia arose from a non-rhythmic neuromodulatory arousal system: Implications for the evolution of specialized behavior. Amer. Zool 2001, 41:962-975.

62. Newcomb JM, Fickbohm DJ, Katz PS: Comparative mapping of serotoninimmunoreactive neurons in the central nervous systems of nudibranch molluscs. J Comp Neurol 2006, 499:485-505.

63. Jing J, Vilim FS, Cropper EC, Weiss KR: Neural analog of arousal: persistent conditional activation of a feeding modulator by serotonergic initiators of locomotion. J. Neurosci 2008, 28:12349-12361.

64. Jing J, Gillette R: Escape swim network interneurons have diverse roles in behavioral switching and putative arousal in Pleurobranchaea. J. Neurophysiol 2000, 83:13461355.

65. Popescu IR, Frost WN: Highly dissimilar behaviors mediated by a multifunctional network in the marine mollusk Tritonia diomedea. J Neurosci 2002, 22:1985-1993.

66. Tian LM, Kawai R, Crow T: Serotonin-immunoreactive CPT interneurons in Hermissenda: identification of sensory input and motor projections. J Neurophysiol 2006, 96:327-335.

67. Satterlie RA: Organization of the dorsoventral musculature in the wings of the pteropod mollusc Clione limacina. Invertebrate Biology 2015, 134:282-290.

68. Satterlie RA, Norekian TP: Serotonergic modulation of swimming speed in the pteropod mollusc Clione limacina. III. Cerebral neurons. J. Exp. Biol 1995, 198:917930.

69. Newcomb JM, Katz PS: Different functions for homologous serotonergic interneurons and serotonin in species-specific rhythmic behaviours. Proc. R. Soc. B 2009, 276:99-108.

70. Katz PS: Tritonia swim network. Scholarpedia 2009, 4:3638.

71. Getting PA: A network oscillator underlying swimming in Tritonia. In Neuronal and Cellular Oscillators. Edited by Jacklet JW: Marcel Dekker, Inc; 1989:215-236.

72. Jing J, Gillette R: Central pattern generator for escape swimming in the notaspid sea slug Pleurobranchaea californica. J. Neurophysiol 1999, 81:654-667.

73. Newcomb JM, Sakurai A, Lillvis JL, Gunaratne CA, Katz PS: Homology and homoplasy of swimming behaviors and neural circuits in Nudipleura molluscs. Proc. Natl. Acad. Sci. U. S A 2012, 109 Suppl 1:10669-10676.

74. Lillvis JL, Katz PS: Parallel evolution of serotonergic neuromodulation underlies independent evolution of rhythmic motor behavior. J Neurosci 2013, 33:2709-2717.

* This paper shows that two sea slug species that independently evolved a particular form of swimming also have serotonergic neuromodulation intrinsic to their swim CPG circuit. A third species, which does not exhibit this form of swimming, lacked the modulation even though it has homologous neurons. This suggests that the presence of serotonergic neuromodulation could be a necessary condition for the operation of the swim CPG. 
75. Katz PS: Evolution of central pattern generators and rhythmic behaviours.

Philos.Trans.R.Soc.Lond B Biol.Sci. 2016, 371:20150057.

** This review discusses the evolution of a class of circuits, namely CPGs to illustrate general concepts about neural circuit evolution. In some cases, there has been independent evolution of circuit motifs to produce similar behaviors, whereas in other cases different circuit designs produce similar behaviors. Evidence supports the model that behavior and neural circuitry are independent levels of biological organization.

76. Katz PS, Lillvis JL: Reconciling the deep homology of neuromodulation with the evolution of behavior. Curr Opin. Neurobiol 2014, 29C:39-47.

77. Sakurai A, Newcomb JM, Lillvis JL, Katz PS: Different roles for homologous interneurons in species exhibiting similar rhythmic behaviors. Curr. Biol 2011, 21:1036-1043.

78. Sakurai A, Katz PS: Phylogenetic and individual variation in gastropod central pattern generators. J Comp Physiol A Neuroethol.Sens. Neural Behav Physiol 2015, 201:829839.

79. Sakurai A, Gunaratne CA, Katz PS: Two interconnected kernels of reciprocally inhibitory interneurons underlie alternating left-right swim motor pattern generation in the mollusc Melibe leonina. J. Neurophysiol 2014, 112(6):131728:1317-1328.

* This manuscript provides a detailed explanation of the microcircuitry underlying the swimming behavior of a nudibranch mollusc. This simple behavior is controlled by a CPG with only eight neurons, four in each half of the brain. The organization is not a simple half-center, but rather contains two sets of mutually inhibitory interneurons that fire $25 \%$ out of phase with each other, resulting in a four beat rhythmic for a two-phase behavior.

80. Sakurai A, Katz PS: The central pattern generator underlying swimming in Dendronotus iris: A simple half-center network oscillator with a twist. Journal of Neurophysiology In Press.

** This paper describes the central pattern generator (CPG) underlying swimming in the nudibranch mollusc, Dendronotus iris. The CPG consists of only four neurons, two in each of the pedal ganglia that fire in left right alternation. Each neuron inhibits its contralateral counterpart. The organization is interesting for several reasons. First, it is the simplest example of a half center network oscillator; none of the neurons exhibits bursting properties. Second the two "halves" of the half-center have neurons on both sides of the brain. Finally, the organization and functioning of the CPG is different from that of the closely related Melibe leonina even though the CPGs contain putatively homologous neurons and the behavioral output is similar.

81. Kocot KM, Aguilera F, McDougall C, Jackson DJ, Degnan BM: Sea shell diversity and rapidly evolving secretomes: insights into the evolution of biomineralization. Frontiers in Zoology 2016, 13:1-10. 
Fig. 1

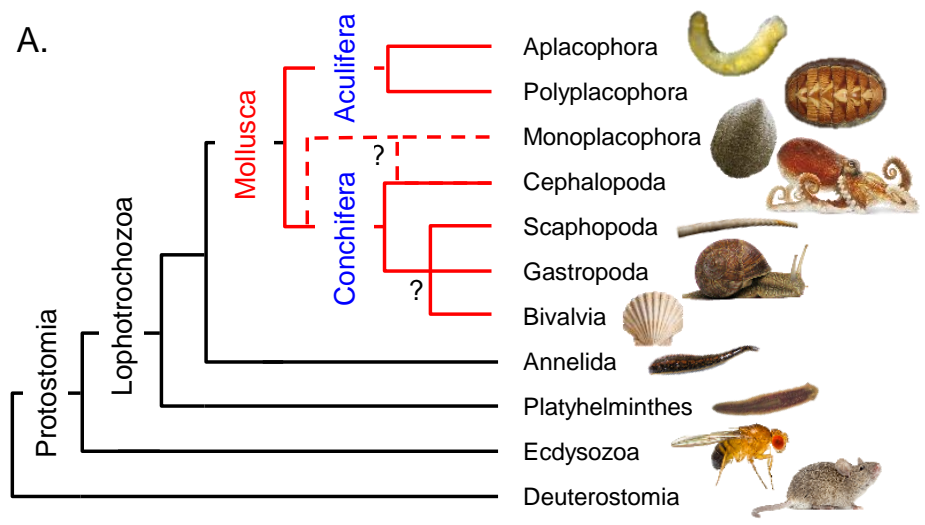

B.

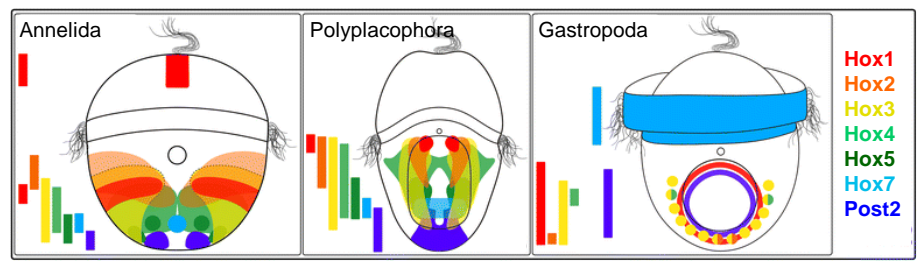


Fig. 2
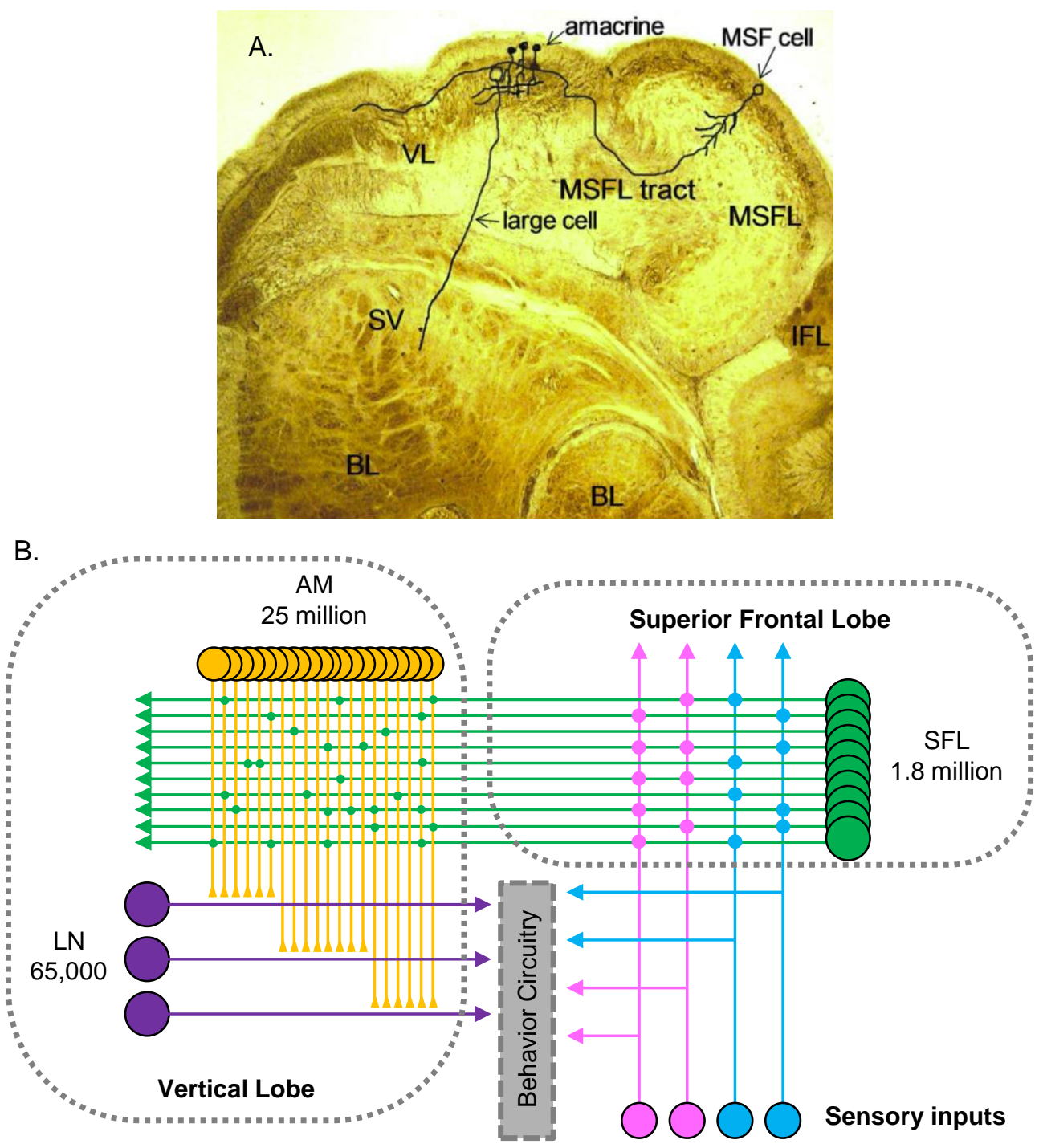
Fig. 3

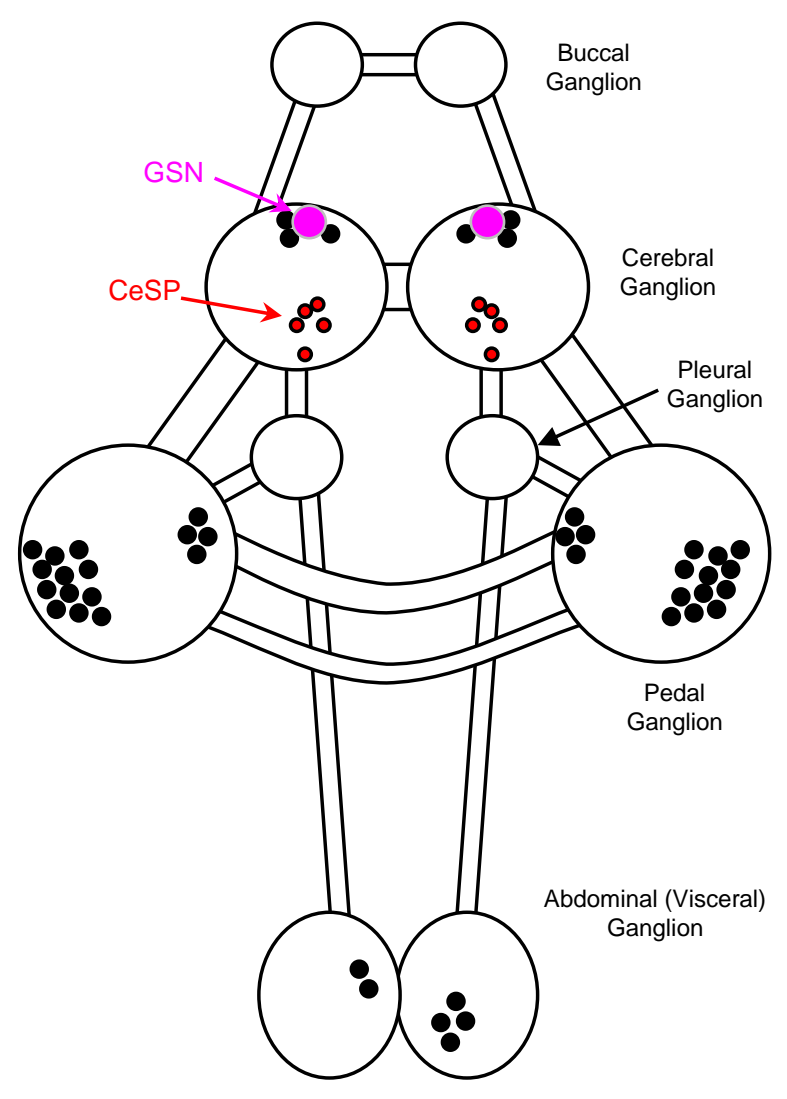


Fig. 4

A.

Melibe

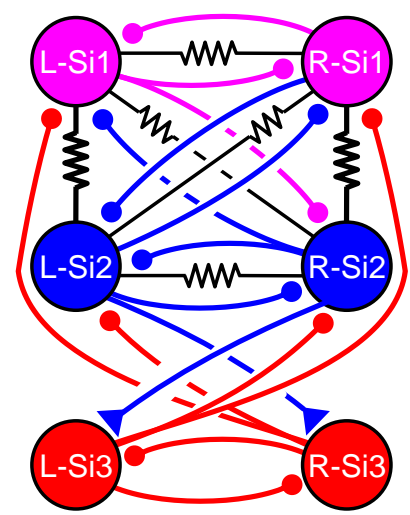

C.

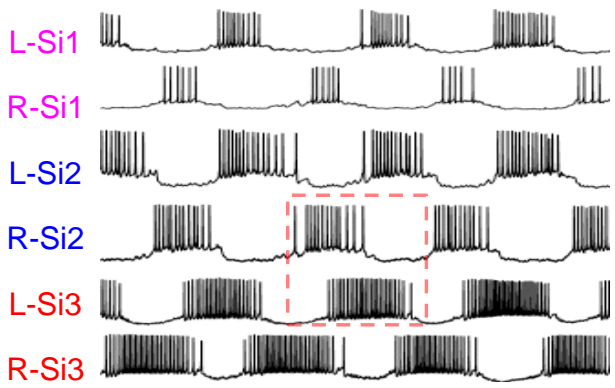

B. Dendronotus

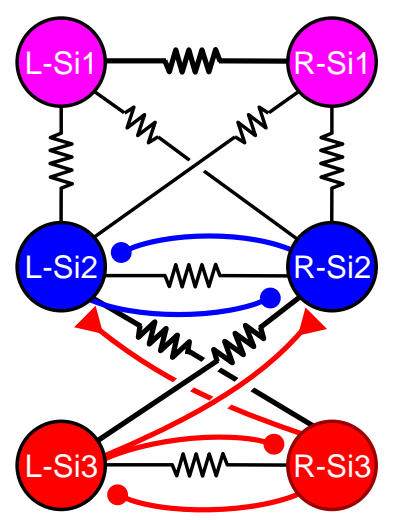

D.

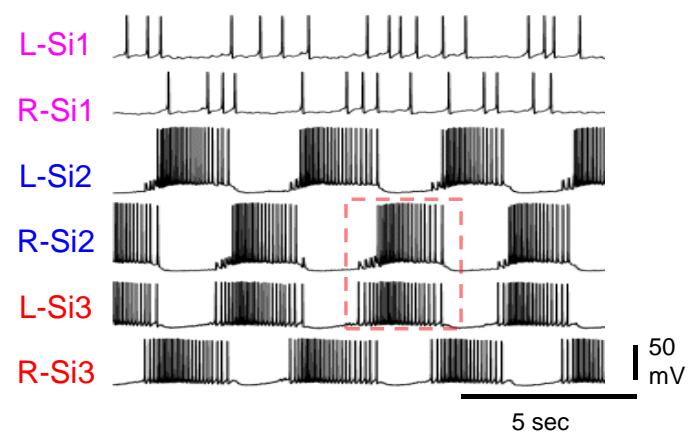

